\title{
Investigation and management of pulmonary infiltrates following bone marrow transplantation: an eight year review
}

\author{
J H Campbell, N Blessing, A K Burnett, R D Stevenson
}

\begin{abstract}
Background-Although pulmonary infiltrates are common in bone marrow transplant recipients and add significantly to the morbidity and mortality of this group of patients, there is uncertainty as to the most appropriate investigation and a lack of information on the effects of investigations on management and outcome.
\end{abstract}

Methods-All bone marrow transplant recipients from one institution referred for respiratory investigation between 1982 and 1990 were reviewed.

Results-Of 204 bone marrow transplant recipients 27 developed pulmonary infiltrates which failed to respond to broad spectrum antibiotics. All were examined by bronchoscopy and bronchoalveolar lavage. A specific diagnosis was made in 20 cases, 17 with an infective cause and three with a non-infective aetiology. In 17 of the 27 episodes these investigations led to a positive change in treatment, but in only five did these changes result in patient survival beyond one month. Eighteen of the 20 deaths were due to progressive respiratory failure of an infective aetiology in 14 and non-infective in four.

Conclusions-Bronchoscopy and bronchoalveolar lavage are effective in establishing a diagnosis, but the impact on overall survival is disappointingly poor.

(Thorax 1993;48:1248-1251)

Department of Respiratory Medicine J H Campbell R D Stevenson

Bone Marrow Transplant Unit N Blessing

A K Burnett

Glasgow Royal Infirmary, Glasgow G31 2ES

Reprint requests to Dr J H Campbell, c/o M Floor Reception, Royal Hallamshire Hospital, Glossop Road, Sheffield S10 2JF

Received 11 March 1993 Returned to authors 28 May 1993 Revised version received 25 August 1993 Accepted 31 August 1993
Pulmonary infiltrates developing in bone marrow transplant recipients continue to pose considerable problems in diagnosis and management, and add significantly to the morbidity and mortality in this group of patients. ${ }^{1}$ Reports of several large series of bone marrow transplant programmes have led to the development of a timetable which predicts peak incidence of various infectious agents, dependent mainly on the stage of immunological reconstitution. ${ }^{2-6}$ This grading of relative risk has helped to rationalise the diagnostic approach to these difficult sensus on the most appropriate investigation and scant information on the effects of such investigations on patient management and its outcome. patients. Despite this, there is a lack of con-
To address these uncertainties we have $\vec{\circ}$ reviewed our experience in investigating pul- $\overrightarrow{-}$ monary infiltrates in bone marrow transplanto recipients over an eight year period; particular emphasis has been placed on the effect of invasive investigations on patient manage ment and survival.

\section{Methods}

From January 1982 to December $1990204-$ patients underwent bone marrow transplantation (110 allogeneic, 94 autologous) at our尺̊ institution. Twenty seven patients (15 men,,$\frac{3}{\circ}$ mean age 32 years, range 17-49) developed䛼 pulmonary infiltrates which failed to respond $\vec{\bullet}$ to broad spectrum antibiotics and required specialised respiratory investigation. The pretransplantation haematological diagnoses are outlined in table 1. Treatment regimes used to induce remission varied. The preparativen pretransplantation regime used was cyclo-零 phosphamide $(60 \mathrm{mg} / \mathrm{kg} \times 2$ intravenously $) \stackrel{2}{\Rightarrow}$ and total body irradiation (median dose 14 윽 Gy, range 12-14.4) for those with haematological malignancies and cyclophosphamide alone for aplastic anaemia. Three patients received melphalan $\left(130 \mathrm{mg} / \mathrm{m}^{2}\right)$ instead ofo cyclophosphamide. The clinical details are summarised in table 2 . Investigation of theo respiratory incident included bacterial culture. of blood, sputum, urine and throat swabs, and serological tests for virus, Mycoplasma, and Legionella. In each episode fibreoptic? bronchoscopy and bronchoalveolar lavage were performed. All patients received supplemental oxygen and saturation was continu- $N$ ously monitored with pulse oximetry. Lavage was performed with warmed sterile saline $(60-180 \mathrm{ml})$ instilled into a subsegmental ${ }^{\omega}$ bronchus. Thrombocytopenic patients (platelet count $\left.<100 \times 10^{9} / 1\right)$ undergoing transbronchiak

Table 1 Pretransplantation haematological diagnoses

\begin{tabular}{|c|c|c|}
\hline Diagnosis & Stage & $\begin{array}{l}\text { No. of } \\
\text { patients }\end{array}$ \\
\hline Acute myeloid leukaemia & $\begin{array}{l}\text { Remission } \\
\text { Relapse }\end{array}$ & $\begin{array}{l}9 \\
3\end{array}$ \\
\hline $\begin{array}{l}\text { Acute lymphoblastic } \\
\text { leukaemia }\end{array}$ & $\begin{array}{l}\text { Remission } \\
\text { Relapse }\end{array}$ & $\begin{array}{l}4 \\
0\end{array}$ \\
\hline Chronic myeloid leukaemia & Chronic phase & 6 \\
\hline Lymphoma & Remission & 3 \\
\hline Aplastic anaemia & - & 2 \\
\hline
\end{tabular}


Table 2 Clinical presentation of pulmonary infiltrates in 27 patients following bone marrow transplantation

\begin{tabular}{lc}
\hline Clinical presentation & No. of patients \\
\hline Cough & $20(74)$ \\
Breathlessness & $12(44)$ \\
Haemoptysis & $4(15)$ \\
Pleurisy & $2(7)$ \\
Weight loss & $2(7)$ \\
Fever & $22(81)$ \\
Arterial $\mathrm{PO}_{2}<8 \mathrm{kPa}$ (on air) & $14(52)$ \\
White cell count $<0.5 \times 10^{9} / 1$ & $11(41)$ \\
Platelet count $<50 \times 10^{\circ} / 1$ & $16(59)$ \\
Chest radiographic pattern & $19(70)$ \\
Diffuse & $8(30)$ \\
Localised & \\
\hline
\end{tabular}

Values in parentheses are percentages.

lung biopsies were given platelet cover, biopsies being performed under fluoroscopic control. All lavage samples were investigated with Gram and acid-fast stains and bacterial, mycobacterial and fungal cultures. The lavaged cells were examined cytologically and stained with Grocott's silver stain. For viral culture the fluid was inoculated into cultures of human lung embryo fibroblasts. From 1986 onwards samples were examined by a direct fluorescent antibody test with monoclonal antibodies to Legionella pneumophila and Pneumocystis carinii.

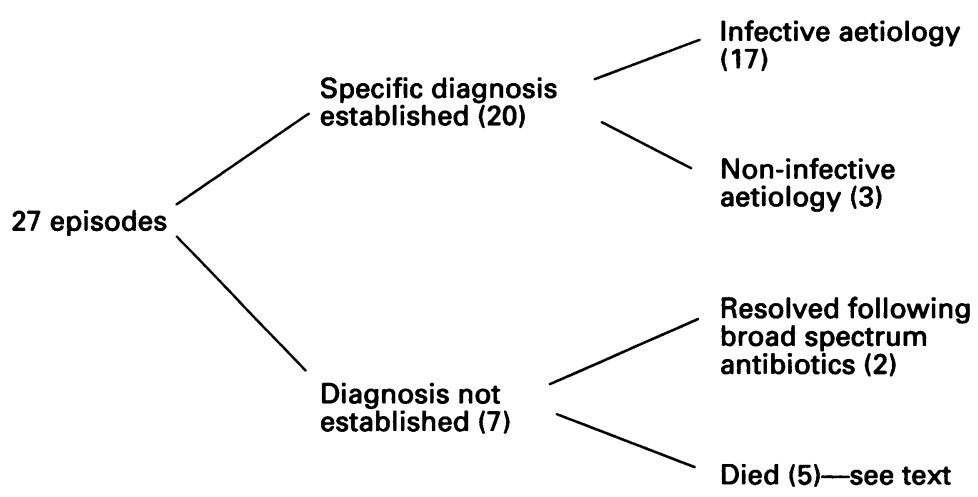

Causes of pulmonary infiltrates in 27 patients following bone marrow transplantation.

Table 3 Infective agents isolated from bronchoalveolar fluid

\begin{tabular}{|c|c|c|c|}
\hline Organism(s) & $\begin{array}{l}\text { Time from bone marrow } \\
\text { transplantation (days) }\end{array}$ & $\begin{array}{l}\text { Type of } \\
\text { graft }\end{array}$ & No. \\
\hline \multicolumn{4}{|l|}{ Mixed: } \\
\hline $\begin{array}{l}\text { Pseudomonas } \\
\text { + parainfluenza } 111\end{array}$ & 224 & Allogeneic & 1 \\
\hline $\begin{array}{l}\text { Acinetobacter } \\
+ \text { parainfluenza } 111\end{array}$ & 168 & Allogeneic & 1 \\
\hline $\begin{array}{l}\text { Aspergillus } \\
+ \text { parainfluenza } 111\end{array}$ & 84 & Allogeneic & 1 \\
\hline $\begin{array}{l}\text { Aspergillus } \\
+ \text { Staphylococcus }\end{array}$ & 112 & Allogeneic & 1 \\
\hline \multicolumn{4}{|l|}{ Viral: } \\
\hline Cytomegalovirus & $37 ; 188$ & Allogeneic & 2 \\
\hline Parainfluenza 111 & $14 ; 140$ & Allogeneic & 2 \\
\hline Influenza B & 42 & Autologous & 1 \\
\hline Herpes simplex & 14 & Autologous & 1 \\
\hline \multicolumn{4}{|l|}{ Fungi: } \\
\hline Aspergillus fumigatus & 82 & Allogeneic & 1 \\
\hline Candida albicans & 7 & Autologous & 1 \\
\hline \multicolumn{4}{|l|}{ Bacteria: } \\
\hline Klebsiella & 280 & Autologous & 1 \\
\hline Pseudomonas aeruginosa & 280 & Allogeneic & 1 \\
\hline Haemophilus influenzae & 114 & Autologous & 1 \\
\hline Legionella pneumophila & 7 & Allogeneic & 1 \\
\hline Pneumocystis carinii & 120 & Allogeneic & 1 \\
\hline
\end{tabular}

\section{Results}

A specific diagnosis was made in 20 of the 27 episodes investigated (figure). Fibreoptic bronchoscopy with bronchoalveolar lavage was the principal technique by which a diagnosis was made. Transbronchial lung biopsy was performed in four cases in the early years, but added little to the diagnostic yield and is no longer used routinely.

No diagnosis was made in seven episodes, two of which resolved after further courses of broad spectrum antibiotics and a presumptive diagnosis of treated bacterial infection was made. The remaining five cases died without a diagnosis. Four underwent a necropsy which showed that one died from a massive gastrointestinal haemorrhage secondary to peptic ulcer, post mortem examination revealing resolving pneumonia, two had nonspecific interstitial pneumonitis, and one patient had disseminated candidiasis including lung involvement. In one case necropsy was refused.

\section{INFECTIVE AGENTS ISOLATED}

Infection accounted for 18 of the 27 episodes $(67 \%), 17$ of these being correctly identified before death (table 3 ). Viral agents, particularly parainfluenza 111 virus were the commonest pathogens isolated. Two patients had combined parainfluenza viral and Gram negative bacterial pneumonia. Cytomegalovirus pneumonitis was identified in only two cases. Aspergillus was the commonest fungus isolated (four of six episodes). In three episodes aspergillus infection was associated with another organism-Pneumocystis carinii (one), parainfluenza 111 (one), Staphylococcus aureus (one)-all three patients had chronic graft versus host disease. In the three episodes of aspergillus pneumonitis diagnosed before death, examination of bronchoalveolar lavage fluid revealed aspergillus hyphae and culture was positive. In two cases bronchoscopy revealed characteristic widespread tracheal and endobronchial ulcers, biopsies of which confirmed invasive aspergillosis and in one of these bronchoscopy was used to assess response and guide the duration of treatment. The radiographic pattern was not specific for any given aetiology but a focal infiltrate was more common in bacterial pneumonia (four of six episodes) than either viral (one of six) or fungal (one of four) cases.

Overall, four of the 17 infective episodes responded to specific treatment (defined as resolution of radiographic changes combined with a patient being discharged home and surviving at least six months). Of the remaining 13 the median duration of survival from the time of bronchoscopy was 18 days (range 3-74).

\section{NON-INFECTIVE AETIOLOGY}

This accounted for five of the $27(19 \%)$ episodes, three of which were correctly identified before death. These were cytotoxic drug (busulphan) induced pneumonitis (one), pulmonary alveolar haemorrhage (one), and obliterative bronchiolitis plus non-specific 
fibrosis (one). Cytotoxic drug induced pneumonitis and obliterative bronchiolitis were diagnosed from transbronchial lung biopsy specimens; both these patients subsequently died of progressive respiratory failure. The patient with drug induced pneumonitis recovered with steroids. The two undiagnosed cases died, and necropsies revealed nonspecific interstitial pneumonitis.

\section{COMPLICATIONS}

There were no life threatening complications related to bronchoscopy and allied procedures. Three patients developed a pneumothorax following transbronchial lung biopsy, but all resolved without intervention.

\section{EFFECT ON MANAGEMENT}

In 17 of the 27 episodes (63\%) these investigations led directly to a positive change in treatment as follows: steroid treatment (one); significant change in antibiotic regime (12); interferon therapy (two); cytomegalovirus immunoglobulin (two). In a further four cases the absence of a specific pathogen from the bronchoalveolar lavage was accepted as excluding serious opportunistic infection and escalation of the antibiotic regime was avoided; this decision was borne out by the subsequent favourable outcome in these patients. However, in only five of the $27 \mathrm{did}$ these changes in treatment result in the patient surviving beyond one month. This correlated with the high mortality for this group as a whole.

\section{Discussion}

The investigation and management of pulmonary infiltrates in a group of autologous and allogeneic bone marrow transplant recipients is described. Bronchoscopy and bronchoalveolar lavage provided the diagnosis in 20 of the 27 episodes investigated-a diagnostic rate of $74 \%$ which is similar to other reported series. ${ }^{7}$ Infection was the major aetiological factor, accounting for $67 \%$ of cases, but the pattern of infectious agents differed from other series in several important aspects. Previous studies have cited cytomegalovirus as the most common pathogen isolated, accounting for $40-56 \%$ of infective cases with a high associated mortality. ${ }^{36-9}$ In contrast, although we found viral agents to be the commonest organism isolated (primary agents six, mixed infection three) cytomegalovirus pneumonia was diagnosed in only two cases. All except one of our fatal cases was subjected to necropsy and, in view of the severity of cytomegalovirus infection in bone marrow transplantation recipients, it is unlikely that patients not receiving specific treatment would improve spontaneously. Pneumocystis carinii pneumonia was also less common than previously documented. These differences probably reflect changing practices in transplant programmes, in particular the use of cytomegalovirus negative products and prophylactic Septrin. ${ }^{10}$ Fungal pneumonitis remains a problem despite the use of laminar airflow and prophylactic antibiotics.
Although identified by bronchoalveolar lavage in four cases, fungal infection accounted for the two undiagnosed infections in this series. One patient developed aspergillus pneumonia as a preterminal event superimposed on treated Pneumocystis carinii pneumonia. In two cases we were particularly impressed by 음 the widespread involvement of the tracheobronchial tree by aspergillus infection; one of $\overrightarrow{\vec{z}}$ these patients survived the episode and $\stackrel{\vec{T}}{+}$ bronchoscopy proved valuable in the assessment of the response to amphotericin and $\overline{\bar{N}}$ was used to guide the duration of treatment.

The role of lung biopsy in identifying the $\propto$ cause of pulmonary infiltrates in immuno- के compromised patients remains controversial. $\overrightarrow{0}$ Confusion has arisen from the reporting of $\vec{\overrightarrow{ }}$ immunocompromised patients with various $\vec{\sigma}$ underlying diseases, often with very different $\overrightarrow{\vec{*}}$ predispositions, the yield from invasive inves- $x$ tigations being influenced by selection of patients and the spectrum of underlying dis- $\vec{N}$ ease. We have previously shown the impor- $\vec{N}$ tance of transbronchial lung biopsy in $\infty$ diagnosing pulmonary infiltrates in patients 우 with lymphoma and others have reported the benefits of open lung biopsy in bone marrow

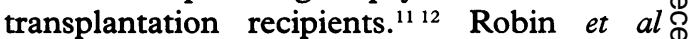
make the point that, if patient survival is used 3 as the outcome measure, few, if any, of the published series show a clear benefit from $\overrightarrow{0}$ lung biopsy. ${ }^{13}$ The high incidence of pro- $\frac{\omega}{\omega}$ found thrombocytopenia following bone marrow transplantation makes transbronchial lung biopsy particularly difficult in this group and it was performed on only four cases in our series. Although it added little additional $\stackrel{\circ}{\varnothing}$ information to bronchoalveolar lavage, there $\stackrel{\varrho}{\Rightarrow}$ are insufficient data to draw any firm conclusions from our findings. Lavage alone is $\frac{3}{2}$ unlikely to establish a non-infective diagnosis, so it seems reasonable to consider lung biopsy as a secondary procedure in patients with negative lavage who continue to deteriorate.

In this group of bone marrow transplant $\frac{0}{-}$ recipients pulmonary investigations significantly influenced subsequent management $\delta$ with a positive change in treatment being instituted in 17 of 27 episodes. However, the $\frac{9}{7}$ overall outcome of this group was very disap- $\rightarrow$ pointing and in only five cases did these changes in treatment result in patient survival $\bar{N}$ beyond one month. This poor overall outcome reflects the severity of illness in the group as a whole. All patients had abnormal $\mathrm{W}$ chest radiographs on presentation and over half were critically ill with respiratory failure. Others have echoed the low survival once respiratory failure is established, and Milburn et $a l^{7}$ stressed the importance of considering bronchoscopy and bronchoalveolar lavage in $\mathbb{\Phi}$ symptomatic patients with normal chest $\frac{?}{10}$ radiographs. Whether earlier investigation $\frac{\varrho}{\sigma}$ and treatment in our group would have materially altered the outcome is not known.

Bronchoscopy and bronchoalveolar lavage are effective in establishing the cause of pul-흘 monary infiltrates in bone marrow transplant ${ }^{+}$ recipients, but their impact on overall survival remains disappointingly poor. 
1 Editorial. Lung disease following allogeneic marrow transplantation. Lancet 1989;ii:1368-9.

2 Winston DJ, Gale RP, Meyer DV, Young LS. Infectious complications of human bone marrow transplantation. Medicine 1979;58:1-31.

3 Krowtic MJ, Rosenow EC, Hoagland C. Pulmonary complications of bone marrow transplantation. Chest 1985;87:237-46.

4 Weiner RS, Bortin MM, Gale RP, Gluckman E, Key $\mathrm{HEM}$, Kolb $\mathrm{HJ}$, et al. Interstitial pneumonitis after bone marrow transplantation: assessment of risk factors. Ann Intern Med 1986;104:168-75.

5 Lum L. The kinetics of immune reconstitution after human marrow transplantation. Blood 1987;69:369-80.

6 Wingard JR, Mellits ED, Sostrin MB, Chen DYH, Burns WA, Santas GW, et al. Interstitial pneumonitis after allogeneic bone marrow transplantation. Medicine 1988;67:175-86.

7 Milburn HJ, Prentice HG, Dubois RM. Role of bronchoalveolar lavage in the evaluation of interstitial pneumonitis in recipients of bone marrow transplants.
Thorax 1987;42:766-72.

8 Neiman PE, Reevers W, Ray G, Flournoy N, Lerner KG, Sale $\mathrm{GE}$, et al. A prospective analysis of interstitial pneumonia and opportunistic viral infection among recipients of allogeneic bone marrow grafts. $\mathcal{F}$ Infect Dis 1977;136:754-67.

9 Meyers JD, Flournoy W, Thomas ED. Non bacterial pneumonia after allogeneic marrow transplantation: review of ten year's experience. Rev Infect Dis 1982;4:1119-32.

10 Winston DJ, Ho WG, Gale RP, Champlin RE. Prophylaxis of infection in bone marrow transplants. Eur 7 Cancer Clin Oncol 1988;24:S15-S23.

11 Campbell JH, Raina V, Banham SW, Cunningham D, Soukop M. Pulmonary infiltrates-diagnostic problems in lymphoma. Postgrad Med $\mathcal{F} 1989 ; 65: 881-4$.

12 Clark JG, Crawford SW. Diagnostic approaches to pulmonary complications of marrow transplantation. Chest 1987;91:477-9.

13 Robin D, Burke CM. Lung biopsy in immunosuppressed patients. Chest 1986;89:276-8. 